Preprints of the

Max Planck Institute for

Research on Collective Goods

Bonn 2008/25

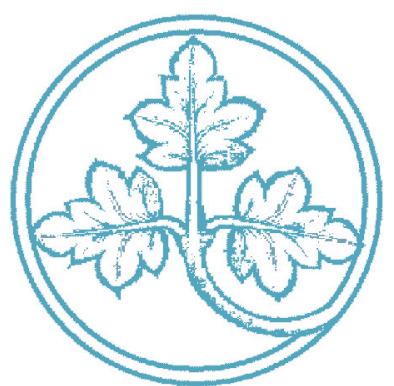

Semi-collusive advertising and pricing in experimental duopolies

Andreas Nicklisch

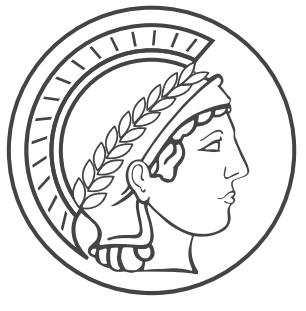




\section{Semi-collusive advertising and pricing in experimental duopolies}

Andreas Nicklisch

June 2008 


\title{
Semi-collusive advertising and pricing in experimental duopolies*
}

\author{
Andreas Nicklisch ${ }^{\dagger}$
}

\begin{abstract}
This article tests experimentally whether a high degree of collusion on advertisement expenditures facilitate tacit price collusion in duopoly markets. Two environments are tested, in which the size of the spillover between advertising expenditures is varied. The results show that the competitiveness of advertising and prices are significantly higher when the advertising spillover is higher than the price spillover than when advertising spillover is lower than the price spillover. In the second environment, a higher degree of advertising collusion leads for experienced players to a higher degree of price collusion. In the first environment, players behave at most semi-collusively, that is, if at all, they collude on advertising, but compete over prices.
\end{abstract}

Keywords: Advertising, duopoly competition, experimental economics, price collusion, semi-collusive markets

[JEL] D43, L13, M37

${ }^{*}$ The author would like to thank Christoph Engel and Hans-Theo Normann for helpful comments.

${ }^{\dagger}$ Max Planck Institute for Research on Collective Goods, Kurt-Schumacher-Straße 10, D-53113 Bonn, Germany; email nicklisch@coll.mpg.de 


\section{Introduction}

This article analyzes the relation between two important issues of industrial organizations, advertising decisions and tacit collusion. Particularly, I will investigate whether a high degree of collusion on advertising expenditures facilitates tacit price collusion. My concern about this issue is that advertising expenditures may be used to signal firms' intentions with respect to the competitiveness of prices. For this purpose, a simple experimental setup is developed which allows to test this question.

The effect of advertising for price or quantity competition has been subject to well-established literature (e.g., Comanor \& Wilson, 1979). The main discussion has been attributed to the question whether advertising increases or decreases the concentration of markets, that is, whether advertisements offer differentiation opportunities for products of new market entrants (e.g., Nelson, 1974, Klein \& Leffler, 1981), or whether established brands create market entry barriers (e.g., Cubbin, 1981, Schmalensee, 1981, 1983). Following the seminal articles by Salop and Stiglitz (1977) and Varian (1980), contemporary studies focus on the relation between advertising and price dispersion on markets for homogeneous goods (e.g., Baye \& Morgan, 2001, Iyer \& Pazgal, 2003). Pricing is examined when firms can advertise them at a high cost on markets with two types of customer, informed customers who buy at the cheapest price and naive customers who choose the product randomly. Here, the analysis reveals that firms optimally mix the provision and non-provision of information on prices. Indeed, experimental studies by Morgan, Orzen and Sefton (2006a, 2006b) find price dispersion for homogeneous products, when firms can advertise their prices. However, the frequency with which they choose to advertise is higher than predicted, resulting in advertising strategies that are too aggressive.

I consider a setting where firms decide on advertising and prices sequentially; firms do not advertise the products' prices, but run some kind of promotion campaign. Knowing the entire vector of advertising choices, they decide on prices. Hence, firms can impede competition in two dimensions, advertising and prices. Along both dimensions, firms may collude, that is, they increase advertising expenditures (prices) such that they jointly maximize their profit. Moreover, the advertising decision can be considered as a commitment device indicating an attempt to collude on prices. The issue of tacit collusion has been a major field for experimental industrial organization (see the survey article by Holt, 1995, and Huck, Normann \& Oechssler, 2004, Engel, 2007, for a contemporary overview) offering ample evidence (Selten \& Stöcker, 1986) of stable cooperation even in the case of a known finite number of interactions. Despite the lack of precise empirical data on price collusion, 
the experimental method offers the additional advantage of control for a certain aspect that facilitates or impedes collusion. Previous examples analyze the effect of cheap talk communication on cooperation rates (e.g., Holt \& Davis, 1990, and Cason \& Davis, 1995) or the impact of firm mergers on cooperation rates (e.g., Fonseca \& Normann, 2008). Overall, Bertrand price competition tends to induce a higher degree of collusion than Cournot quantity competition (Suetens \& Potters, 2007). Closely related to my study are recent laboratory experiments that explore whether cooperative research and development expenditures leads to price collusion (e.g., Suetens, 2007). They test a standardized version of the two-stage model of d'Aspremont and Jacquemin (1988) and Kamien et al. (1992), where two firms compete over prices and sell differentiated products. The degree of price collusion is compared between a treatment, where duopolists form binding contracts over research and development expenditures - which reduce production costs - and a treatment where no contracts could be formed. Results indicate that the degree of price collusion is significantly higher when contracts are formed than when no contracts have been formed and when no contracts could be formed.

In this paper I will apply a modified version of the two-stage model of d'Aspremont and Jacquemin (1988) to investigate the relation between pricing decisions and advertisement decisions. Firms competing for differentiated products run promotion campaigns. Advertising expenditures of one firm increases the demand for its own as well as for competing products. Thus, unlike earlier experimental studies on the effect of capacity commitments on price setting (e.g., Davis, 1999, Muren, 2000, Anderhub et al., 2003), there is a "double" spillover effect in my setting: first in terms of prices (i.e., increasing the own price increases the demand for the opponent's product), and second in advertising expenditures (i.e., increasing own expenditures increases the demand for the product of the opponent). Treatment conditions will vary the size of the spillover effect for advertising expenditures (henceforth denoted as investments). It is important to stress an important difference between pricing decisions and investment decisions. Between each investment decision, firms will be allowed to adjust prices for several periods. Therefore, I will denote them as price changes within a promotion campaign. Particularly, in the experiment, within each promotion campaign, firms simultaneously decide for five consecutive periods on prices. This allows us to analyze the degree of price collusion at the beginning, in the middle and at the end of a promotion campaign. Notice that the setting does not enable firms to communicate or to form contracts on investments; today, cooperative advertising of firms is the rare exception. 
Thus my setting will measure the "pure" relation between the degree of price collusion and the degree of investment collusion.

The experimental results are two-fold. In the environment, where the size of the investment spillovers is lower than the size of the price spillovers, a higher degree of investment collusion facilitates price collusion for experienced players (i.e., in later periods of the experiment). Furthermore, collusion is built up subsequently over the promotion campaign, that is, a higher degree of price collusion is induced by a higher degree of investment collusion in the middle and at the end, but not at the the beginning of the promotion campaign. On the contrary, in the environment, where the size of the investment spillovers is higher than the size of the price spillovers, a higher degree of investment collusion negatively influences the degree of price collusion. If at all, players behave semi-collusively, that is, they collude on advertising expenditures, but compete in prices. Compared with the environment where investment spillovers are high, the overall degree of collusion for both variables is higher when investment spillovers are low.

The remainder of the article is organized as follows: Section 2 introduces the theoretical model. Section 3 reports the experimental setting and discusses research hypotheses. Section 4 describes the results of the series of laboratory experiments. Finally, Section 5 concludes the article.

\section{The model}

As the theoretical benchmark for my experiment serves an adaptation of the duopoly market for differentiated products applied by Suetens (2007). Selling differentiated products, two firms compete over prices for a finite number of periods, $t=1, \ldots T$. Firm $i$ and its competitor $-i$ choose prices simultaneously facing the following linear demand curve:

$$
q_{i}^{t}\left(p_{i}^{t}, p_{-i}^{t}\right)=\max \left\{A_{i}^{t}-p_{i}^{t}+\alpha p_{-i}^{t}, 0\right\}
$$

where $p_{i}^{t}$ denotes the price of firm $i$ in period $t, p_{-i}^{t}$ the competitor's price in period $t$, and $\alpha$ the degree of price spillovers, $0<\alpha<1$. The variable $A_{i}^{t}$ denotes $i$ 's market size in period $t$. It is assumed that firms can invest in advertising activities which increase their market size, as well as their competitor's. Let $m_{i}^{t}\left(m_{-i}^{t}\right)$ denote firm $i$ 's investment (the competitor's investment) in period $t$ and $A_{0}$ the initial market size, then $i$ 's market size is defined as

$$
A_{i}^{t}=A_{0}+m_{i}^{t}+\beta m_{-i}^{t},
$$


where $\beta, 0<\beta<1$, characterizes the degree of investment spillovers between the product of $i$ and $-i{ }^{1}$ Thus, advertisements of firm $i$ also increase the market size for firm $-i$ 's product, and vice versa. Importantly, firms' decisions are restricted such that they are not allowed to change $m_{i}^{t}$ for a fixed number of periods, $w$. After each decision on investments, firms make $w$ price decisions where the investment remains unchanged, that is, $m_{i}^{t}=m_{i}^{t+1}=\ldots=m_{i}^{t+w}$ for $t=1, w+1,2 w+1, \ldots$. Therefore, I will denote investment decisions as promotion campaigns lasting for several periods.

With respect to firms' payoffs, I assume that firms have a linear production cost function and a quadratic cost function for advertising. Replacing the quantities by the demand function yields for firm $i$ in period $t$ the following profit:

$$
\pi_{i}^{t}=\left(A_{i}^{t}-p_{i}^{t}+\alpha p_{-i}^{t}\right)\left(p_{i}^{t}-c\right)-k\left(m_{i}^{t}\right)^{2},
$$

where $c$ denotes the marginal cost for production and $k$ the cost parameter for investments, respectively. ${ }^{2}$

Firms play a two-stage game. In the first stage, they simultaneously choose investments and then, knowing the vector of investment choices, they simultaneously set their prices. Let us solve the game by backward induction. For given investments, both firms will choose prices according to their best reply function. This will lead to the subgame perfect Nash equilibrium for prices in each price-setting period. Partial derivation of the profit with respect to prices of firm $i$ and firm $-i$ yields an equilibrium price $^{3} p^{N}$ that equals

$$
p^{N}=\frac{2}{4-\alpha^{2}}\left(A_{i}^{t}+c\right)+\frac{\alpha}{4-\alpha^{2}}\left(A_{-i}^{t}+c\right) .
$$

Likewise, both firms will choose investments according to their best reply function anticipating optimal behavior of their competitors. Substitution the price in the profit function (3) with the equilibrium price according to equation (4), and maximization with respect to investments leads to the symmetric subgame perfect Nash equilibrium for investments $m^{N}$ that equals in each investment-setting period

$$
m^{N}=\frac{\mu_{1}+\mu_{2}}{\mu_{1}^{2}-\mu_{2}^{2}} \frac{A_{0}(2+\alpha)-c\left(2-\alpha-\alpha^{2}\right)}{4-\alpha^{2}},
$$

\footnotetext{
${ }^{1}$ Notice that I model two complementary investments. For an analysis of substitutive investments, see, e.g., Nagel \& Vriend (1999).

${ }^{2} A_{0}>c \geq 0$ and $k \geq \max \left(1, \frac{(1+\beta)^{2}}{4(1-\alpha)}\right)$.

${ }^{3}$ Notice that the subgame perfect equilibrium allows asymmetric prices if investments are asymmetric. However, if both players simultaneously optimize investments, the subgame perfect Nash equilibrium yields symmetric investments, and, consequently, leads to a symmetric subgame perfect Nash equilibrium price.
} 
where $\mu_{1}=2 k-\frac{2+\alpha \beta}{4-\alpha^{2}}$, and $\mu_{2}=\frac{2 \beta+\alpha}{4-\alpha^{2}}$.

A second benchmark solution is offered by prices and investments that jointly maximize the profit of both firms. Although experiments frequently observe some degree of price collusion, this benchmark is not an equilibrium in the strict game-theoretic sense, since firms interact for a finite number of periods. Assuming that firms collude in price setting, partial derivation of the joined profit function of firm $i$ and firm $-i$ with respect to prices yields

$$
p^{C}=\frac{A_{i}^{t}+(1-\alpha) c}{2-2 \alpha}
$$

If firms expect to collude in the $w$ price-setting periods, they replace the price in the profit function (3) with collusive price according to equation (6). Maximizing the sum of both profit functions with respect to investments leads then to the collusive investments $m^{C}$ that equals in each investment-setting period

$$
m^{C}=\frac{(1+\beta)\left(A_{0}+\alpha c-c\right)}{4 k(1-\alpha)-(1+\beta)^{2}} .
$$

Both the subgame perfect Nash equilibrium in prices/investments and collusive pricing/investing describe two extreme points in the priceinvestment space. One alternative that has been frequently discussed in the literature, are semi-collusive markets (e.g., Fershtman \& Muller, 1986, Kamien et al., 1992). Here, firms cooperate in one dimension, for instance research or advertising expenditures, while they compete in another dimension, typically prices. Applying this idea to a semi-collusive market where firms compete in prices but collude on investments requires that I introduce the price $p^{N}$ in the profit function (3). Maximization of the sum of both profit functions with respect to investments leads to the semi-collusive investment level, $m^{S}$, that equals

$$
m^{S}=\frac{\left(2 \mu_{3}-\frac{2(1-\alpha) \mu_{3}^{2}}{1+\beta}\right)\left(A_{0}+c\right)-\alpha c}{2 k+2(1-\alpha) \mu_{3}^{2}-2(1+\beta) \mu_{3}}
$$

for $\mu_{3}=\frac{1+\beta}{2-\alpha}$.

Summarizing the results, one obtains $p^{C}>p^{N}$ and $m^{C}>m^{S}>m^{N}$.

\section{Hypotheses and experimental procedure}

For the experiment, the parameter values of the model are specified as $c=1, k=2, A_{0}=6, T=60$, and $w=5$. Therefore, a promotion campaign lasts for five periods, while players decide twelve times on 
Table 1: Theoretical benchmarks for prices and investments

\begin{tabular}{cccccc} 
& $m^{N}$ & $m^{S}$ & $m^{C}$ & $p^{N}$ & $p^{C}$ \\
\hline LOW & 1.17 & 2.49 & 3.09 & 5.68 & 10.52 \\
HIGH & 1.28 & 5.68 & 8.42 & 6.12 & 20.82 \\
\hline
\end{tabular}

investments. With respect to spillover effects, I introduce two treatment condition denoted as LOW and HIGH. In both settings, the degree of price spillover remains constant at $\alpha=0.5$. In the LOW condition $\beta=$ 0.3 , that is, the investment spillover is weaker than the price spillover, whereas, in the HIGH condition, the investment spillover $\beta=0.7$, that is, the investment spillover is higher than the price spillover.

The theoretical analysis shows that higher investment spillover increases the incentives for collusion considerably, while changing the Nash equilibria only slightly (i.e., $\frac{\partial m^{N}}{\partial \beta}<\frac{\partial m^{C}}{\partial \beta}$ ). Particularly, given the experimental parameters, $m^{C}$ increases from 3.09 (LOW) to 8.42 (HIGH), whereas $m^{N}$ increases from 1.17 (LOW) to 1.28 (HIGH). Accordingly, profits for collusion are more than doubled (from 26.2 to 54.5), but remain approximately the same for the subgame perfect Nash equilibrium (19.2 versus 22.9). All theoretical benchmarks for prices and investments corresponding to the parameter values are reported in Table 1. Notice that empirical studies challenge the theoretical results. Research on investments in product- or process-enhancing technology has found that the degree of cooperation decreases when investment spillovers are high (e.g., Cassiman \& Veugelers, 2002, Kaiser, 2002). Interpreting advertising expenditures as product-enhancing technology, one can speculate that decreasing (financial) incentives facilitates a higher degree of investment collusion under experimental conditions. To resolve the conjecture I will test the following hypothesis.

$H_{1}$ : The degree of investment collusion is higher in the HIGH than in the LOW condition.

In order to explore the influence between the degree of investment collusion and the degree of price collusion, I will define two measures for collusion. The degree of investment collusion of player $i$ in period $t$ is defined as

$$
\kappa_{i}^{t}:=\frac{\tilde{m}_{i}^{t}-m^{N}}{m^{C}-m^{N}}
$$

where $\tilde{m}_{i}^{t}$ denotes the experimentally observed investment of player $i$ in period $t$. Note that $\kappa_{i}^{t}=0$ indicates $\tilde{m}_{i}^{t}=m^{N}$ and $\kappa_{i}^{t}=1$ indicates $\tilde{m}_{i}^{t}=m^{C}$. 
When defining the degree of price collusion, one has to consider that players are informed on investments of both firms before they choose prices; the degree of price collusion are functions of $\tilde{m}_{i}^{t}$ and $\tilde{m}_{-i}^{t}$. Thus, I define the degree of price collusion of player $i$ in period $t$ as

$$
\lambda_{i}^{t}:=\frac{\tilde{p}_{i}^{t}-p^{N}\left(\tilde{m}_{i}^{t}, \tilde{m}_{-i}^{t}\right)}{p^{C}\left(\tilde{m}_{i}^{t}, \tilde{m}_{-i}^{t}\right)-p^{N}\left(\tilde{m}_{i}^{t}, \tilde{m}_{-i}^{t}\right)},
$$

where $\tilde{p}_{i}^{t}$ denotes the experimentally observed price, and $p^{N}\left(\tilde{m}_{i}^{t}, \tilde{m}_{-i}^{t}\right)$ $\left(p^{C}\left(\tilde{m}_{i}^{t}, \tilde{m}_{-i}^{t}\right)\right)$ is calculated using equation (4) (equation (6)) for the investments in period $t$. Again, one finds $\lambda_{i}^{t}=0$ for $\tilde{p}_{i}^{t}=p^{N}$ and $\lambda_{i}^{t}=1$ for $\tilde{p}_{i}^{t}=p^{C}$ given the actually observed investments $\tilde{m}_{i}^{t}, \tilde{m}_{-i}^{t}$. The two measures will allow us to analyze the effect of investment collusion on price collusion. That is, if players deviate from the subgame perfect Nash equilibrium and collude in investments, does this facilitate a higher degree of price collusion? On the other hand, referring to the concept of semi-collusive markets, tacit investment collusion may not influence the degree of price collusion at all; players may collude in investments, but compete over prices. To analyze the effect, I introduce

$\mathrm{H}_{2}$ : A high degree of investment collusion, $\kappa_{i}^{t}$, corresponds with high degree of price collusion, $\lambda_{i}^{t}$.

I will test $\mathrm{H}_{2}$ for three different "points" of the promotion campaign: at the beginning of a promotion campaign (i.e., in the period of the investment decision), in the middle of a promotion campaign (i.e., in the third period of the promotion campaign), and at the end of a promotion campaign (i.e., in the period before new investment decisions are made). One may speculate whether prices decrease or increase more likely in the course of a promotion campaign. The first case suggests that players learn subsequently to play their best responses, whereas the second case suggests that price collusion is built up subsequently.

Experiments were conducted in the laboratory of the Max Planck Institute Jena of economics, Germany, in spring 2005. ${ }^{4}$ In total, 48 subjects, mostly undergraduate students from the University of Jena in their third or fourth year of studying mathematics, natural sciences, or economics, participated in the experiment. Each subject participated only in one treatment condition; 12 player pairs participated in the LOW condition, 12 player pairs in the HIGH condition. As the market mechanism is rather complex, only experienced subjects who had previously completed at least four experiments (but no oligopoly experiment) participated in this experiment. Instructions were handed out to participants

\footnotetext{
${ }^{4}$ They were computerized using the software package zTree (Fischbacher, 2007); subjects were recruited using the software package ORSEE (Greiner, 2004).
} 
and read out aloud thereafter. ${ }^{5}$ Participants' questions concerning the experiments were then answered privately by the instructors. To check their full understanding of the instructions, participants were then asked to answer a multiple-choice questionnaire. Before participants answered the questionnaire, it was made clear that there was no competition in answering the questions, but that the purpose was to enhance the understanding of the experimental rules. Wrong answers were privately explained and corrected before the experiment started. During the experiment and for answering the questionnaire, subjects were provided with a simple calculator, pen, and paper.

At the beginning of the experiment, two anonymous players randomly formed a pair that remained matched for the entire 60 periods. In the first and every fifth consecutive period, subjects were simultaneously asked to choose the investment level; values could range between 0 and 9, with 0.01 as the smallest incremental. Subjects knew that for the following four periods, they could not change this value. Then, players were informed about their own and their competitor's investment. Players then simultaneously determined their prices; values could range between 0 and 25, with 0.01 as the smallest incremental. Finally, subjects were informed on their own payoff as well as their competitor's price and payoff. At the end of the experiment, accumulated profits were converted at an exchange rate of 120 units $=1$ Euro. Before the experiment started, subjects were asked to agree on covering potential, accumulated losses across the entire 60 periods by clerical work at the institute. All subjects agreed, but none accumulated losses. For playing 60 periods, subjects needed approximately 90 minutes (including the time needed for questionnaire) and earned on average 9.93 Euros (standard deviation 2.48 Euros) in the HIGH and 7.63 Euros (standard deviation 1.89 Euros) in the LOW condition.

\section{Experimental results}

I will first provide an overview of the data by means of average figures, while then comparing the degree of investment collusion across treatment conditions and the relation between investment and price collusion in greater detail. Figure 1 shows in the left column the development of average investments for the HIGH condition, and in the right column the development of average investments for the LOW condition over periods; the dotted black horizontal line indicates the Nash investment levels, while the grey lines the average \pm one standard deviation. Overall, average investments are close to the $m^{N}$, but the figures suggest

\footnotetext{
${ }^{5}$ Instructions are provided in the Appendix.
} 
that average investment decreases when investment spillovers increase. Indeed, the statistical comparison shows a significant difference between the average investments in LOW, 1.24 and in HIGH, $1.06 .^{6}$

Figure 1: Promotion investments in (a) LOW and (b) HIGH
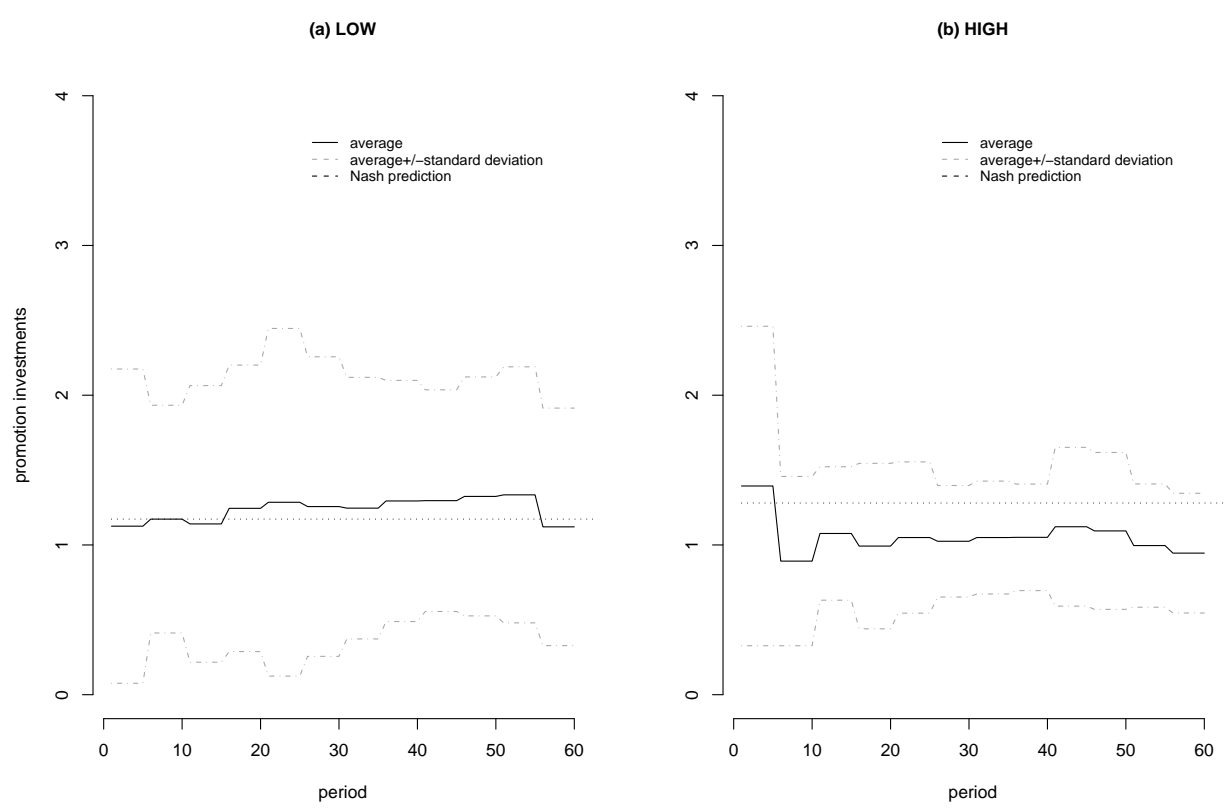

When analyzing average prices for the two treatment conditions, results are similar. Considering the range of potential prices, both are also close to the Nash equilibrium given Nash equilibrium investment. ${ }^{7}$ The development of prices is shown in Figure 2, left column LOW and right column HIGH, where the dotted horizontal lines indicate the Nash price level for the Nash level of investments and the grey lines the average \pm one standard deviation. Unlike investments, average prices do not differ significantly across treatment conditions (5.66 for LOW and 5.71 for HIGH). ${ }^{8}$ Thus, although the LOW condition yields against theoretical predictions on average higher investments than the HIGH condition, this does not lead to significant differences in average prices.

To test $H_{1}$ for investments, I normalize investments $\tilde{m}_{i}^{t}$ according to $\kappa_{i}^{t}$ as defined in equation (9). Apparently, $\kappa_{i}^{t}=1$ indicates full collusion

\footnotetext{
${ }^{6} p<0.001$, Wilcoxon signed rank test comparing period averages, two-sided.

${ }^{7} \mathrm{~A}$ precise rating for the degree of price collusion respecting the actual investments chosen by both players will be provided below.

${ }^{8} p=0.45$, Wilcoxon signed rank test comparing period averages, two-sided.
} 
Figure 2: Prices in (a) LOW and (b) HIGH
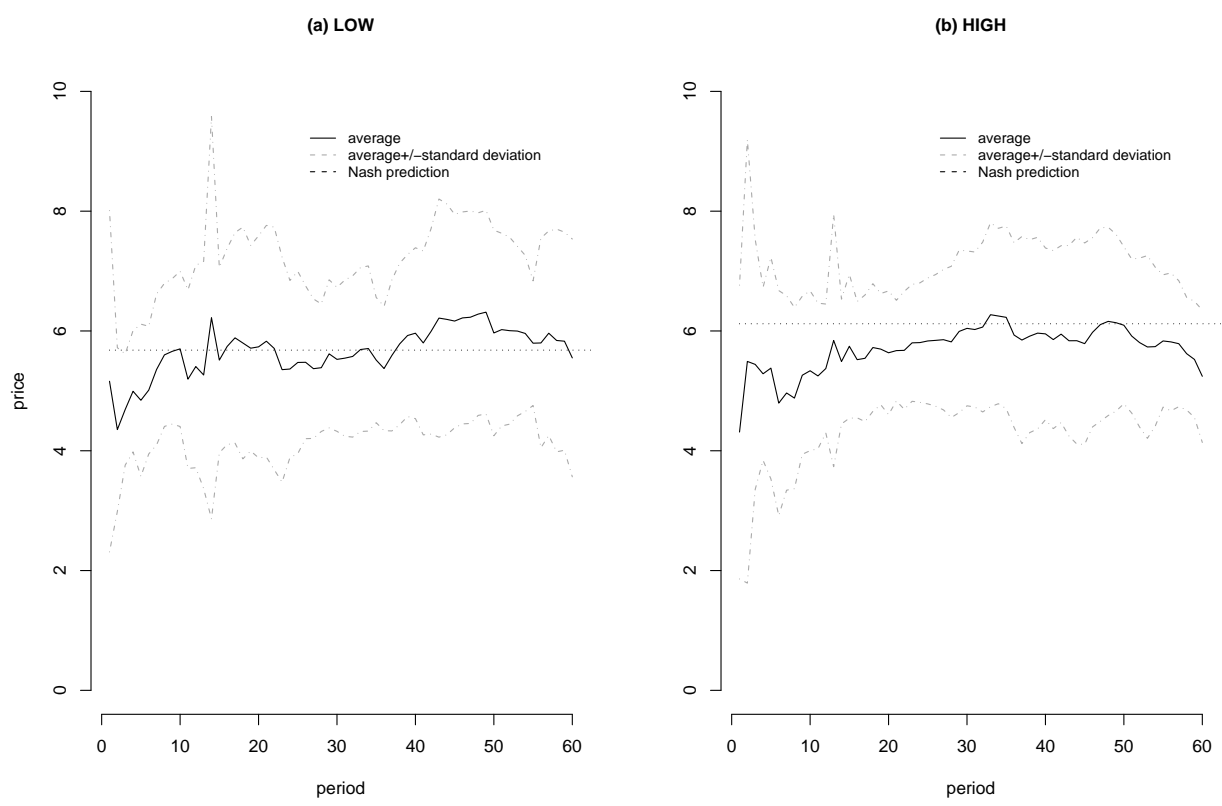

on investments, while $0<\kappa_{i}^{t}<1$ indicates some degree of investment collusion. Finally, $\kappa_{i}^{t} \leq 0$ shows no collusion on investments, and $\kappa_{i}^{t}>1$ non-optimal over-investment with respect to joint profit maximization. Notice that $\kappa_{i}^{t}\left(m^{S}\right)=0.69$ in the LOW and $\kappa_{i}^{t}\left(m^{S}\right)=0.62$ in the $\mathrm{HIGH}$ condition. I will classify $\kappa_{i}^{t}$ with respect to categories $k_{x}$, where $x=$ $\{-1 / 6,1 / 6,3 / 6,5 / 6,7 / 6,9 / 6\}$ denotes the upper bound of disjunctive categories. That is, if $\kappa_{i}^{t} \leq-1 / 6 \kappa_{i}^{t} \in k_{-1 / 6}$, if $-1 / 6<\kappa_{i}^{t} \leq 1 / 6$ $\kappa_{i}^{t} \in k_{1 / 6}$, and so forth. Hence, $m^{N}$ lies in the center of category $k_{1 / 6}$, $m^{C}$ lies in the center of category $k_{7 / 6}$, while $m^{S}$ lies approximately in the center of category $k_{5 / 6}$ (for both treatment conditions). Table 2 shows the number of investment choices for categories $k_{x}$.

Based on the categorization results, I have to reject $H_{1}$. Increasing the investment spillover effect in the HIGH condition does not lead to an increasing degree of collusive investments. Rather, almost all investments are classified in the $k_{1 / 6}$ category in the HIGH condition, while there is considerably more variance in the classification of investments in the LOW condition. Overall, the experimental data tentatively supports the empirical observations. The average degree of collusion is lower in the HIGH than in the LOW condition; averages for LOW increase from -0.036 in the first half of periods to 0.014 in the second half of periods, whereas averages for the HIGH remain at -0.037 for the first half 
Table 2: Categorization of investments according to $k_{x}$

\begin{tabular}{cccccccc} 
& & $k_{-1 / 6}$ & $k_{1 / 6}$ & $k_{3 / 6}$ & $k_{5 / 6}$ & $k_{7 / 6}$ & $k_{9 / 6}$ \\
\hline period 1-30 & LOW & 58 & 40 & 32 & 4 & 4 & 6 \\
& HIGH & 2 & 138 & 2 & 2 & 0 & 0 \\
period 31-60 & LOW & 42 & 52 & 38 & 0 & 10 & 2 \\
& HIGH & 0 & 142 & 2 & 0 & 0 & 0 \\
\hline period 1-60 & LOW & 100 & 92 & 70 & 4 & 14 & 8 \\
& HIGH & 2 & 280 & 4 & 2 & 0 & 0 \\
\hline
\end{tabular}

Notice: Categories $k_{x}$ classify investments such that $x$ denotes the upper bound of disjunctive categories.

of periods and -0.04 for the second half. Notice that there is a weakly significant difference for the second half of periods between treatment conditions, ${ }^{9}$ but no significant difference for the first half and for the average of all periods $(-0.01$ under LOW compared to -0.038 under HIGH). ${ }^{10}$

Now let us contrast $\kappa_{i}^{t}$ with the $\lambda_{i}^{t}$ at the beginning, in the middle and at the end of the promotions campaign (i.e., the first, third, and last price decision after investments have been adjusted). The first panel of Figure 3 shows the experimentally observed $\kappa_{i}^{t} / \lambda_{i}^{t}$ combinations as gray dots at the beginning of a promotion campaign, the second panel the $\kappa_{i}^{t} / \lambda_{i}^{t}$ combinations in the middle of a promotion campaign, and the third panel the $\kappa_{i}^{t} / \lambda_{i}^{t}$ combinations at the end of a promotion campaign, where $i$. provides the results for the LOW condition and ii. the results for the HIGH condition. Small circles indicate the $\kappa_{i}^{t}\left(m^{N}\right) / \lambda_{i}^{t}\left(p^{N}\right)$ combination, small triangles the $\kappa_{i}^{t}\left(m^{C}\right) / \lambda_{i}^{t}\left(p^{C}\right)$ combination, and small crosses indicate the $\kappa_{i}^{t}\left(m^{S}\right) / \lambda_{i}^{t}\left(p^{N}\right)$ combination (characterizing semi-cooperative markets).

With respect to the $\kappa_{i}^{t}$ dimension, Figure 3 shows the large concentration of investments at the Nash equilibrium level in the HIGH condition. In contrast, investments are less concentrated in the LOW condition. ${ }^{11}$ With respect to the $\lambda_{i}^{t}$ dimension, there is not such a clustering for any treatment condition. However, I find for prices some convergence to the Nash equilibrium over the promotion campaigns in the HIGH condition,

\footnotetext{
${ }^{9} p=0.09$, Mann-Whitney-U rank sum test comparing period averages, two-sided.

${ }^{10} p=0.70$ and $p=0.13$, Mann-Whitney-U rank sum tests comparing period averages, two-sided.

${ }^{11}$ Recall that investments do not change within a promotion campaign so that all panels are identical for the $\kappa_{i}^{t}$ dimension.
} 
Figure 3: Experimentally observed $\kappa_{i}^{t}$ and $\lambda_{i}^{t}$ combinations
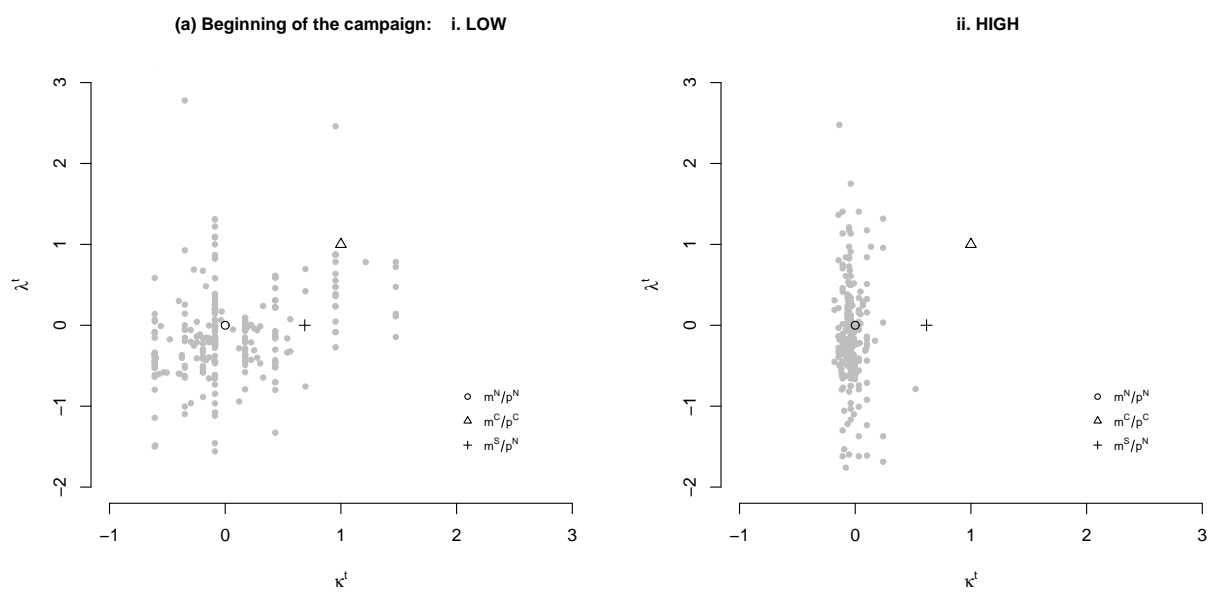

(b) Middle of the campaign: i. LOW

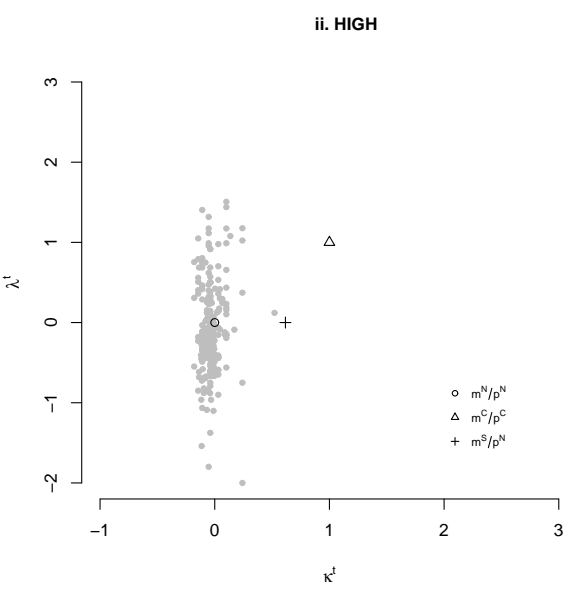

(c) End of the campaign: i. LOW

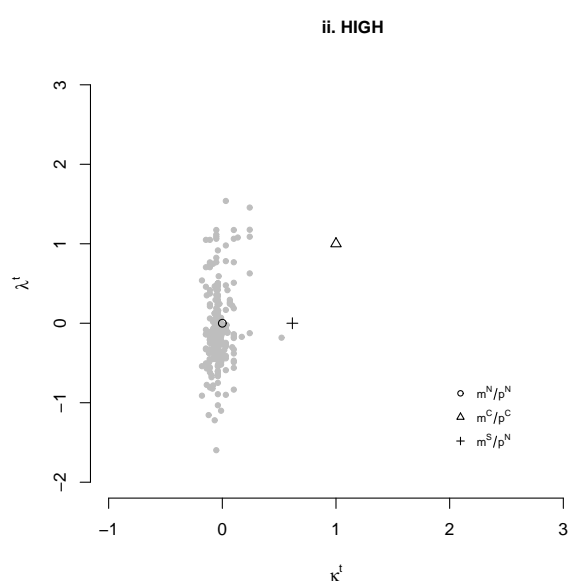


since the average distance of prices to the Nash equilibrium decreases weakly significant over the promotion campaign. No significant decrease can be found in the LOW condition. Specifically, at the beginning of the promotion campaign, the mean $\lambda_{i}^{t}$ is -0.12 in the HIGH condition $(-0.096$ in the LOW condition), increases to $-0.054(-0.075)$ in the middle of the campaign, and remains at $-0.056(-0.072)$ at the end of the campaign. The difference between $\lambda_{i}^{t}$ at the beginning and the end of the campaign is significant for the HIGH condition, but insignificant for the LOW condition. ${ }^{12}$ Thus, in extension of result for investments, I find also for prices a stronger convergence to the best respond in the HIGH than in the LOW condition. Overall, I find the following

Result 1: Increasing the investment spillovers tends to decrease the distance to the Nash equilibrium both for investments and prices.

In order to explore the relation between the two variables, I will regress the the degree of price collusion on the degree of investment collusion controlling for other factors. Specifically, I will estimate the coefficients of the linear individual random-effect model

$$
\lambda_{i}^{t}=\mathbf{x}_{i}^{\prime} \beta+\varsigma_{i, t}
$$

where $\mathbf{x}_{i}$ denotes the matrix of regressors, $\beta$ for the vector of (true) coefficients and $\varsigma_{i, t}$ for the unobserved individual random effect. I estimate the model for the LOW and the HIGH condition separately. As independent variable, $\kappa_{i}^{t}$ is tested. Furthermore, the different points of the promotion campaign are considered by means of the two dummy variables $\delta_{\text {middle/end }}$ and $\delta_{\text {end }}$. The first variable is defined such that $\delta_{\text {middle/end }}=1$ if the pricing decision comes either from the middle or the end of the promotion campaign and 0 otherwise, while $\delta_{\text {end }}=1$ if the pricing decision comes from the end of the promotion campaign and 0 otherwise. Thus, significant coefficients for the first variable (or interactions with this variable) indicate significant differences in pricing behavior between the beginning of the promotion campaign and the later points of the promotion campaign, whereas significant coefficients for the second variable (or interactions with this variable) indicates significant differences in behavior at the end of the promotion campaign. Finally, the variable $t=1, \ldots, 60$ captures temporal effects like learning between early periods and later periods of the experiment.

According to the hypothesis $H_{2}$, one expects the coefficient of $\kappa_{i}^{t}$ to be significantly positive. Particularly, the hypothesis suggests that the positive correspondence between $\kappa_{i}^{t}$ and $\lambda_{i}^{t}$ holds for the beginning, the middle and the end of the promotion campaign. On the other hand, if

\footnotetext{
${ }^{12} p=0.077$ for HIGH and $p=0.79$ for LOW, Wilcoxon signed rank test comparing period averages, two-sided.
} 
we assume that players learn subsequently to play their best response, the coefficients of $\kappa_{i}^{t} \times \delta_{\text {middle/end }}$ and $\kappa_{i}^{t} \times \delta_{\text {end }}$ should be significantly negative. On the contrary, if price collusion is built up subsequently, the two coefficients are expected to be significantly positive. Table 3 reports the results for the two models, LOW and HIGH, respectively. Stars indicate the significance of coefficients; ${ }^{13}$ the number of observation $(n)$ is reported. Finally, the fitness of the models is suggested by the loglikelihood (logLik) and the Akaike information criterion (AIC).

The estimated coefficient for the LOW condition shows that the degree of price collusion is initially negative, that is, the constant term is significantly negative, but increases with progress of the experiment, that is, $t$ is significantly positive. In contrast to $\mathrm{H}_{2}$ the coefficient of $\kappa_{i}^{t}$ is insignificantly positive. This result indicates that a higher degree of investment collusion does not significantly induce a higher degree of price collusion. Yet, the (weakly) significantly positive coefficient of $\kappa_{i}^{t} \times \delta_{\text {middle/end }} \times t$ shows for later periods of the experiment that players learn to collude subsequently in the middle and at the end of the promotion campaign. Here, a higher degree of investment collusion leads to a higher degree of price collusion. Therefore, for experienced players, price collusion is built up subsequently; investment collusion facilitates price collusion in the middle and at the end of the promotion campaign. Overall, the results suggest the following in the LOW condition: Higher degrees of investment collusion do not facilitate higher degrees of price collusion. However, in later periods of the experiment, players increase the degree of collusion over the promotion campaign.

For the HIGH condition, the significant negative constant term indicates also initially a negative degree of price collusion. Again, as shown by the significantly positive coefficients of $t$ and $\delta_{\text {middle/end }}$, the degree of collusion increases both over the promotion campaign and in the course of the experiment. However, with respect to the correspondence between the degree of investment collusion and the degree of price collusion, one finds the opposite results to the estimation for the LOW condition. The significantly negative coefficient of $\kappa_{i}^{t}$ indicates that a higher degree of investment collusion leads to a lower degree of price collusion. Thus, in the HIGH condition, increasing the investments intensifies the price competition. If players collude on investments, which has rarely been observed in the data, this leads to semi-collusive markets where players compete in pricing.

To summarize the regression analysis, the estimation results partly support $\mathrm{H}_{2}$ :

\footnotetext{
$13 * * *$ significant on a 0.01 level, ${ }^{* *}$ significant on a 0.05 level, ${ }^{*}$ significant on a 0.1 level.
} 
Table 3: Coefficients for regression models of $\lambda_{i}^{t}$

\begin{tabular}{|c|c|c|c|}
\hline & & LOW & HIGH \\
\hline \multirow[t]{19}{*}{$\begin{array}{c}\text { independent } \\
\text { variables }\end{array}$} & $\kappa_{i}^{t}$ & $\begin{array}{c}0.16 \\
(0.11)\end{array}$ & $\begin{array}{c}-1.44^{* * *} \\
(0.50)\end{array}$ \\
\hline & $\delta_{\text {middle/end }}$ & 0.01 & $0.09^{* *}$ \\
\hline & & $(0.03)$ & $(0.04)$ \\
\hline & $\delta_{\text {end }}$ & -0.003 & 0.002 \\
\hline & & $(0.04)$ & $(0.04)$ \\
\hline & $t$ & $0.005^{* * *}$ & $0.006^{* * *}$ \\
\hline & & $(0.001)$ & $(0.001)$ \\
\hline & $\kappa_{i}^{t} \times \delta_{\text {middle } / \text { end }}$ & -0.25 & 0.71 \\
\hline & & $(0.15)$ & $(0.70)$ \\
\hline & $\kappa_{i}^{t} \times \delta_{\text {end }}$ & 0.11 & 0.86 \\
\hline & & $(0.16)$ & $(0.73)$ \\
\hline & $\kappa_{i}^{t} \times t$ & 0.002 & 0.02 \\
\hline & & $(0.004)$ & $(0.02)$ \\
\hline & $\kappa_{i}^{t} \times \delta_{\text {middle } / \text { end }} \times t$ & $0.008^{*}$ & -0.008 \\
\hline & & $(0.005)$ & $(0.02)$ \\
\hline & $\kappa_{i}^{t} \times \delta_{\text {end }} \times t$ & -0.007 & -0.01 \\
\hline & & $(0.005)$ & $(0.02)$ \\
\hline & constant & $-0.23^{* * *}$ & $-0.32^{* * *}$ \\
\hline & & $(0.06)$ & $(0.07)$ \\
\hline$n$ & & 864 & 864 \\
\hline logLik & & -588 & -574 \\
\hline $\mathrm{AIC}$ & & 1203 & 1174 \\
\hline
\end{tabular}

Notice: ${ }^{* * *}$ significant on a 0.01 level, ${ }^{* *}$ significant on a 0.05 level, ${ }^{*}$ significant on a 0.1 level; $\log$ Lik of null model: -660 (LOW) and -712 (HIGH). 
Result 2a: In the LOW condition, a high degree of investment collusion leads to a higher degree of price collusion for experienced players; price collusion is built up subsequently over the promotion campaign.

However, I have to reject $\mathrm{H}_{2}$ for the environment with high investment spillovers:

Result 2b: In the HIGH condition, a high degree of investment collusion leads to a lower degree of price collusion; if at all, one finds a semicollusive investment level.

Overall, the experimental results suggest that the investment spillovers crucially influence collusion with respect to both dimensions, advertising expenditures and prices. Along several empirical studies (e.g., Kaiser, 2002), I find a lower degree of investment and price collusion when investment spillovers are high. Thus, high investment spillovers increase the competition as prices and investments are closer to subgame perfect Nash equilibrium. At most, they collude on investments but compete over prices. To the contrary, when investment spillovers are low, a higher degree of investment collusion leads to a higher degree of price collusion for experienced players. Moreover, the degree of price collusion increases subsequently over the promotion campaign.

\section{Conclusion}

In this paper, I analyze the relation between the degree of price collusion and the degree of collusion on advertising expenditures. For this purpose, an experimental duopoly game was tested, where participants were asked to specify simultaneously investments for promotion campaigns. Within each promotion campaign, players had to specify prices repeatedly. I controlled the degree of price collusion at the beginning, in the middle and at the end of the promotion campaign. Experiments were run in two environments, a treatment condition where the size of the investment spillovers is lower than the size of the price spillovers, and a treatment condition where the investment spillovers is higher than the price spillovers. The theoretical analysis shows that the financial incentives for collusion increases enormously in the second environment compared with the first one.

Unlike the theoretical suggestion, in the experiment players collude significantly more in the treatment condition with low than with high investment spillovers. On the contrary, high investment spillovers seem to decrease the distance to the subgame perfect Nash equilibrium. This finding supports previous empirical evidence on the relation between collusive research and developments and the size of the technological spillover (e.g., Cassiman \& Veugelers, 2002).

For the relation between investment and price collusion, the econo- 
metric analysis indicates that a higher degree of investment collusion facilitates price collusion for experienced players in the LOW condition. Particularly in later periods of the experiment, collusion is built up subsequently over the promotion campaign. In the HIGH condition, however, I find the opposite effect; a higher degree of investment collusion influences negatively the degree of price collusion. If at all, players behave semi-collusively, that is, they collude on advertising expenditures, but compete in prices.

In general, my findings suggest an important qualification for the propagation of semi-collusive markets. Analyses have to draw profound attention to the size of the investment spillovers as it is an important factor determining the behavior of market participants. There is considerable empirical evidence for semi-collusion (e.g., Steen \& Sørgard, 1999, find that Norwegian cement producers compete on capacities, but collude on prices). The current results suggest that these markets are characterized by large investment spillovers. On the contrary, the laboratory evidence provides a warning for public authorities dealing with price collusion: price collusion is facilitated by investment collusion when spillovers are low. That is, collusion likely occurs although the joint market structure is less likely to be detected.

\section{References}

[1] Anderhub, V., W. Güth, U. Kamecke \& H.-T. Normann (2003), Capacity choices and price competition in experimental markets, $E x$ perimental Economics 6, 27-52.

[2] d'Aspremont, C. \& A. Jacquemin (1988), Cooperative and noncooperative R\&D in duopoly with spill-overs, American Economic Review 78, 1133-1137.

[3] Baye, M. \& J. Morgan (2001), Information gatekeepers on the internet and the competitiveness of homogeneous product markets, American Economic Review 91, 454-474.

[4] Cason, T.N. \& D.D. Davis (1995), Price communications in a multimarket context: An experimental investigation, Review of Industrial Organization 10, 769-787.

[5] Cassiman, B. \& R. Veugelers (2002), R\& D cooperation and spillovers: Some empirical evidence from Belgium, American Economic Review 92, 1169-1184.

[6] Comanor, W.S. \& T.A. Wilson (1979), The effect of advertising on competition: A survey, Journal of Economic Literature 17, 453-476.

[7] Cubbin, J. (1981), Advertising and the theory of entry barriers, Economica 48, 289-298.

[8] Davis, D.D. (1999), Advance production and Cournot outcomes: an 
experimental investigation, Journal of Economic Behavior and Organization 40, 5979.

[9] Engel, C. (2007), How much collusion? A meta-analysis of oligopoly experiments, Journal of Competition Law and Economics 3, 491-549.

[10] Fershtman, C. \& E. Muller (1986), Capital investments and price agreements in semicollusive markets, The Rand Journal of Economics 17, 214-226.

[11] Fischbacher, U. (2007), z-Tree: Zurich toolbox for ready-made economic experiments, Experimental Economics 10, 171-178.

[12] Fonseca, M.A. \& H.-T. Normann (2008), Mergers, asymmetries and collusion: Experimental evidence, The Economic Journal 118, 387400.

[13] Greiner, B. (2004), An online recruitment system for economic experiments. In K. Kremer \& V. Macho (eds.): Forschung und wissenschaftliches Rechnen 2003, Bericht der Gesellschaft für wissenschaftlichen Datenverarbeitung Göttingen 63, 79-93.

[14] Holt, C.A. (1995), Industrial organization: A survey of laboratory research, in: J. Kagel \& A. Roth (eds.): The Handbook of Experimental Economics, Princeton: Princeton University Press, 349-443.

[15] Holt, C.A. \& D.D. Davis (1990), The effects of non-binding price announcements on posted-offer markets, Economics Letters 34, 307310.

[16] Huck, S., H.-T. Normann \& J. Oechssler (2004), Two are few and four are many: Number effects in experimental oligopolies, Journal of Economic Behavior and Organization 53, 435-446.

[17] Iyer, G. \& A. Pazgal (2003), Internet shopping agents: Virtual colocation and competition, Marketing Science 22, 85-106.

[18] Kaiser, U. (2002), An empirical test of models explaining research expenditures and research cooperation: Evidence for the German servive sector, International Journal of Industrial Organization 20, 747-774.

[19] Kamien, M., E. Muller \& I. Zang (1992), Research joint venture and R\&D cartels, American Economic Review 82, 1293-1306.

[20] Klein, B. \& K. Leffle (1981), The role of market forces in assuring contractual performance, Journal of Political Economy 89, 615-641.

[21] Morgan, J., H. Orzen \& M. Sefton (2006a), A laboratory study of advertising and price competition, European Economic Review 50, 323-347.

[22] Morgan, J., H. Orzen \& M. Sefton (2006b), An experimental study of price dispersion, Games and Economic Behavior 54, 134-158.

[23] Muren, A. (2000), Quantity precommitment in an experimental oligopoly, Journal of Economic Behavior and Organization 41, 
147157.

[24] Nagel, R. \& N.J. Vriend (1999), An experimental study of adaptive behavior in an oligopolistic market game, Journal of Evolutionary Economics 9, 27-65.

[25] Nelson, P. (1974), Advertising as information, The Journal of Political Economy 82, 729-754.

[26] Salop, S. \& J. Stiglitz (1977), Bargains and ripoffs: A model of monopolistically competitive price dispersion, Review of Economic Studies 44, 493-510.

[27] Schmalensee, R. (1981), Economies of scale and barriers to entry, The Journal of Political Economy 89, 1228-1238.

[28] Schmalensee, R. (1982), Product differentiation advantages of pioneering brands, American Economic Review 72, 349-365.

[29] Selten, R. \& R. Stöcker (1986), End behavior in finite prisoners dilemma supergames, Journal of Economic Behavior and Organization 7, 4770.

[30] Steen, F. \& L. Sørgard (1999), Semicollusion in the Norwegian cement market, European Economic Review 43, 1775-1796.

[31] Suetens, S. (2007), Does R\&D cooperation facilitate price collusion? An experiment, Journal of Economic Behavior and Organization in press.

[32] Suetens, S. \& J. Potters (2007), Bertrand colludes more than Cournot, Experimental Economics 10, 71-77.

[33] Varian, H. (1980), A model of sales, American Economic Review 70, 651-659. 


\section{Appendix: Instructions ${ }^{14}$}

Thank you for participating in our experiment. We kindly ask you to refrain from any public statements and attempts to communicate directly with other participants. If you violate this rule, we have to exclude you from the experiment. If you have any questions, please raise your hand, and one of the persons who runs the experiment will come to your place and answer your questions. Please read these instructions carefully. In this experiment, you will earn money based on repeated decisions. How much you will earn depends on your decisions as well as the decisions of another participant.

You will repeatedly interact with another, anonymous participant for 60 periods. The instructions are identical for all participants. The other participant will be randomly assigned to you and will remain with you for the entire experiment.

In this experiment, you as well as the other participant have to sell a product on a market. Your profit equals the number of sold entities of your product multiplied by the price, minus production costs. You have to decide on the price of the product. The price can range between 0 and 25 ECU, with 0.01 as the smallest incremental step. The higher the price you choose, the smaller the number of sold entities per period. Whenever the price exceeds a certain level, you cannot sell any entity at all. However, the number of sold entities increases if your competitor increases the price for her product. In summary, your number of sold entities $\left(q_{\text {own }}\right)$ equals

$$
q_{\text {own }}=6-p_{\text {own }}+0.5 p_{\text {other }},
$$

where $p_{\text {own }}$ denotes the price you choose and $p_{\text {other }}$ the price the other participant chooses. Note that for each entity you sell, there are production costs of 1 ECU. Therefore, your profit $\left(G_{\text {own }}\right)$ is

$$
G_{\text {own }}=q_{\text {own }} \times p_{\text {own }}-1 \times q_{\text {own }} .
$$

In every fifth period, you have the opportunity to invest in your product. We denote your investments as $m_{\text {own }}$. Investments can range between 0 and 9 , with 0.01 as the smallest incremental step. Although you can only change your investments in every fifth period, they increase the number of sold entities in every period. Additionally, the investments of the other participant increase the number of sold entities of your product. The number of sold entities of your product $\left(q_{\text {own }}\right)$ equals

$$
q_{\text {own }}=6+m_{\text {own }}+0.3 m_{\text {other }}-p_{\text {own }}+0.5 p_{\text {other }},
$$

\footnotetext{
${ }^{14}$ Author's translation of the German instructions for the LOw condition.
} 
where $m_{\text {other }}$ denotes the investments of the other participant. ${ }^{15}$ However, in every period, investments also cost $2\left(m_{\text {own }}\right)^{2}$ (not only in every fifth period when you can change them). You participate in the investments of the other participant without any costs. Thus, your profit equals

$$
G_{\text {own }}=q_{\text {own }} \times p_{\text {own }}-1 \times q_{\text {own }}-2\left(m_{\text {own }}\right)^{2} .
$$

Please consider that you may accumulate losses due to unfavorable investment choices. If you earn a negative total profit throughout the entire experiment, you will be asked to pay back this amount by doing clerical work at our institute $(120 \mathrm{ECU}=1$ hour $)$. If you do not accept this rule, please leave the experiment now.

In every first out of five periods (i.e., in periods $1,6,11, \ldots$ ), you will be asked to specify your investments. You will not be asked for this in the subsequent 4 periods. Please note that the level of investments cannot be changed for these 4 periods, though you have to carry the costs for them. In each period, you are then informed on the level of investments you chose as well as that chosen by the other participant. Additionally, you are informed on the investments and prices chosen in the previous period. Then you have to choose the price for your product in this period. Finally, we inform you on your profit in this period, the profit of the other participant, and the accumulated profits. At the end of the experiment, we will exchange all ECUs you earned in the 60 periods at a rate of $120 \mathrm{ECU}=1$ Euro.

Before the first round starts, we will ask you several questions concerning the rules of this experiment in a questionnaire. Please answer them correctly. One of the persons who runs the experiment will come to your place and clarify incorrect answers.

\footnotetext{
${ }^{15}$ In the HIGH condition the equation equals $q_{\text {own }}=6+m_{\text {own }}+0.7 m_{\text {other }}-p_{\text {own }}+$ $0.5 p_{\text {other }}$.
} 